\title{
PROSTITUIÇÃO: CAUSAS E PERSPECTIVAS DE FUTURO EM UM GRUPO DE JOVENS
}

\author{
Gilson de Vasconcelos Torres* \\ Rejane Marie Barbosa Davim** \\ Terêsa Neumann Alcoforado da Costa***
}

TORRES, G.de V.; DAVIM, R.M.B.; COSTA, T.N.A.da. Prostituição: causas e perspectivas de futuro em um grupo de jovens. Rev.latino-am.enfermagem, Ribeirão Preto, v. 7, n. 3, p. 9-15, julho 1999.

Este estudo do tipo descritivo exploratório foi realizado na cidade de Natal/RN, entrevistando-se 10 jovens que fazem programas sexuais nas vias de acesso às praias do Meio e de Ponta Negra. Teve-se como objetivos identificar as razões que as fizeram optar por esta atividade e as perspectivas de futuro desse grupo de jovens. Como principais resultados, identificou-se que a principal causa que levou essas garotas a se prostituirem foi a falta de condições financeiras e, como perspectivas de futuro, as adolescentes aspiram deixar a prostituição, trabalhar, terem uma profissão e uma vida digna. Fica patente, então, a necessidade de uma tomada de decisão por parte dos órgãos responsáveis pelo bem-estar do adolescente, como também, pela sociedade em geral, dando alternativas a essas jovens para que saiam do ramo da prostituição, e principalmente que se evite o ingresso de novas adolescentes nessa atividade.

UNITERMOS: prostituição, adolescência

\section{INTRODUÇÃO}

O propósito em realizarmos um estudo sobre a prostituição na adolescência surgiu ao observarmos com freqüência, a presença de jovens nas principais vias de acesso às praias do Meio e de Ponta Negra, situadas na cidade de Natal capital do Rio Grande do Norte (RN), com a finalidade de fazerem programas sexuais.

A importância deste estudo consiste, então, em despertar a atenção para a problemática do grande número de adolescentes muito jovens no campo da prostituição, como também, trazer subsídios para contribuir no desenvolvimento de novas investigações sobre essa temática, salientando, ainda, a relevância no campo da enfermagem, na medida em que representa uma possibilidade de contribuição ao trabalho com adolescentes.

Observa-se, de certa forma, que o crescente desenvolvimento de nossa cidade, associado ao aumento do turismo regional e local, tem propiciado um incremento significativo da prostituição na adolescência. Todo este problema é compactuado também por vários setores da sociedade, dentre os quais destacam-se as empresas de turismo, rede de hotéis, proprietários de motéis, casas noturnas, cafetões e cafetinas, contribuindo assim, para o aliciamento dessas jovens. Esta problemática vem despertando então, em nossa sociedade, uma grande preocupação pelo crescente ingresso dessas adolescentes nesse ramo de atividade, como também, pelo aumento assustador das doenças sexualmente transmissíveis (DST) e pela síndrome da imunodeficiência adquirida (AIDS).

Considerando-se, então, a prostituição na adolescência como um problema de saúde coletiva, é necessário chamar a atenção das instituições públicas responsáveis pelo Estatuto da Criança e do Adolescente, frente às características desse grupo etário em desenvolvimento, e vulnerável a todos os fatores de riscos a que estão expostos.

Portanto, diante de toda esta problemática, temos como principais objetivos para o nosso estudo:

- Detectar as causas mais freqüentes que as jovens do estudo referem como razões para se prostituírem.

- Identificar as perspectivas de futuro dessas jovens diante da sociedade em que sobrevivem.

\section{REVISÃO DA LITERATURA}

A história da prostituição perdeu-se na poeira do

\footnotetext{
* Professor Assistente do Departamento de Enfermagem/UFRN - Mestre em Enfermagem de Saúde Pública/UFPB - Doutorando em Enfermagem Fundamental da Escola de Enfermagem de Ribeirão Preto da Universidade de São Paulo ** Professora Adjunta do Departamento de Enfermagem/UFRN - Mestre em Enfermagem de Saúde Pública/UFPB

*** Professora do Mestrado - Enfermagem em Saúde Pública/UFPB - Dda. de Saúde Pública. Orientadora do trabalho
} 
tempo, porque é tão antiga quanto a história da humanidade, onde nenhuma civilização escapou à sua convivência e nenhum berço foi respeitado.

Para a CONFERÊNCIA NACIONAL DOS BISPOS DO BRASIL/CNBB (1976), a prostituição vem sendo praticada desde a mais remota antigüidade; na idade média, ela foi oficializada como profissão pelas autoridades, constituindo, assim, uma fonte de renda para o Estado. Durante a Revolução Industrial, a prostituição aumentou em toda a Europa devido ao êxodo rural, às condições de pobreza e a promiscuidade das aglomerações urbanas.

Para FRANÇA (1994), o termo prostituição, deriva do latim prosto, que quer dizer "estar às vistas, $\grave{a}$ espera de quem quer chegar ou estar exposto ao olhar público ... é a prática sexual remunerada habitual e promíscua” (p.145). Sendo assim, a prostituta, para BRAGA (1982) é, essencialmente, "uma mulher que aluga seu corpo para jogos sexuais sem amor” (p.62).

Para PELUSO \& GOLDBERG (1996), o mercado do sexo no Brasil está em ebulição, crescendo a cada dia e encontrando terreno fértil para prosperar os negócios do sexo na era da AIDS, fazendo com que pessoas das mais variadas profissões desistam de suas atividades convencionais para tentarem a sorte nesse ramo.

Uma das formas de se penetrar no mundo da prostituição, segundo BRAGA (1982), é quando as adolescentes chegam aos grandes centros urbanos como migrantes, iludidas pelo trabalho fácil, pelo dinheiro, pelo estudo, porém, associando-se tudo isto a desqualificação profissional, ao problema da documentação irregular e do analfabetismo, as oportunidades de emprego tornamse cada vez mais escassas para essas jovens. Entretanto, a necessidade e a luta pela sobrevivência, são fatores que contribuem para grande parte dessa juventude feminina optar pela prostituição como uma maneira aparentemente mais fácil de sobreviver. Cabe ainda considerar, que as jovens, na busca de trabalho pela sobrevivência, concorrem no mercado com as prostitutas profissionais, procurando também de certa forma, satisfazer o luxo da vida moderna, ingressando assim, nesse mundo de prostituição e drogas.

Fica evidente, portanto, que no Brasil, a prostituição na adolescência alcança níveis muito altos, cerca de 50 mil, nas idades que variam entre 9 e 14 anos. (PROSTITUIÇÃO, 1994). No Nordeste, segundo LAGENEST (1987), a idade média para iniciar a vida na prostituição se situa entre 12 e 14 anos de idade, onde, aos 20 a prostituta já é considerada velha, e aos 30 parece já ter 60 .

Ampliando essa discussão sobre a exploração sexual de adolescentes, VASCONCELOS (1991), afirma, através de sua experiência nesse campo, que há praticamente em todo o Nordeste um elevado índice do turismo sexual, com pelo menos duas formas de agenciamento: a primeira, mais comum, é a promoção de pacotes de turismo que incluem as adolescentes como atração sexual, onde os donos de hotéis, de táxis, de barracas de praias e de boates, forma uma forte rede organizada em torno desse negócio. A segunda é a promessa de casamento de adolescentes com estrangeiros, às quais são levadas para fora do país, principalmente a Alemanha, e lá são destinadas á prostituição. Além do turismo sexual, segundo a mesma autora, aparece também nessa região, a exploração sexual de adolescentes nas casas de drinkes, boates e locais noturnos em geral, que agenciam a prostituição infanto-juvenil. Ocorre em muitos casos, a conveniência de policiais nessa forma de comércio.

GOMES (1996), em seu estudo sobre a prostituição infantil, revela que, entre as meninas prostituídas fazendo parte dos segmentos mais pobres da sociedade, são comuns os casos em que as mães têm que doá-las a parentes ou colocá-las em instituições para serem criadas. Diz ainda o autor que, associando-se às questões sociais, há os conflitos relacionados à família, fazendo com que a pobreza se agrave.

Yannoulas apud GOMES (1996), registra ainda que,

“... a saída de meninas para as ruas aumentou a partir da segunda metade da década de 80 ... e, contrariando a idéia de que o lugar de mulher é em casa, as meninas acabam também indo para as ruas ... ressaltando o quadro de pobreza que as leva a procurar ganhar algum dinheiro (p.129). Sendo assim, nesse conjunto de aprendizagem, elas encontram novas regras, descobrindo, então, que seus corpos são algo negociável, onde, ... a venda do corpo converte-se em uma forma de combater a fome e o frio ...” ( $\mathrm{p} .130)$.

Corroborando essas afirmações, disse Hélio Galvão, apud FRANÇA (1994):

“... que a prostituição vem da pobreza geral, da miséria proletária, da promiscuidade, das habitações coletivas, da falta de educação profissional e de trabalho honesto, dos lares desfeitos e defeituosos, do alcoolismo paterno, da infância desarrimada ... desvirginadas muito cedo, antes mesmo da menarca, são varridas de casa pelos pais intolerantes e arbitrários, aliam-se às más companhias, são ultrajadas pelos patrões sem escrúpulos e pelos chefes que exploram sua dependência ... que respeitam o anonimato e não lhes pede qualquer qualificação, a não ser a de seus dotes físicos" (p.146). 
De comum acordo, no que se refere às condições sócio-econômicas, GASPAR (1985), ao realizar em 1982 uma pesquisa no Rio de Janeiro sobre Garotas de Programas, afirma que:

“... uma situação econômica precária, marcada pela difícil colocação no mercado de trabalho por baixos rendimentos, e muitas vezes, pela condição de arrimo e chefe de família, é uma forte justificativa para o fato de a mulher se dedicar à prostituição ... diante da sua própria situação de penúria e também da de sua família, é necessário que ela se sacrifique por ela e pelos seus. A prostituição surge então como um recurso quase legítimo para a falta de dinheiro” (p.86).

Junto a essas considerações, GOMES (1996) registra em seu estudo, que o fato de “... existir meninas que são sexualmente exploradas, através da prostituição, revela em si um feixe de relações violentas que afigura no plano das ações das pessoas e no campo sócio-econômico-cultural em geral” (p.101).

BOSCO FILHO et al. (1996) em seu trabalho afirmam também que, “...o desencadeamento da crise econômica trouxe para a profissão não só mulheres, mas crianças $e$ adolescentes, de ambos os sexos, que perderam sua infância devido a necessidade de obter capital para sobreviver ...”(p.223), os quais sugerem às autoridades competentes, a construção de políticas sociais eficazes no combate a miséria e as injustiças sociais.

Junto a toda essa situação, não resta dúvidas de que a prática da prostituição, pode, de certa forma, deixar nessas jovens o estigma de prostitutas, colocando nelas a etiqueta de transmissoras. Pouco se discute, entretanto, sobre a possibilidade dela ser mais vítima, do que um agente causal dessa situação.

\section{PROCEDIMENTOS METODOLÓGICOS}

Trata-se de um estudo descritivo exploratório, desenvolvido nas vias de acesso às praias do Meio e de Ponta-Negra, localizadas na cidade de Natal, capital do Estado do Rio Grande do Norte, o qual justifica-se pelo alto índice de prostituição de jovens.

Nossa população foi composta por jovens do sexo feminino que faziam programas sexuais nas vias de acesso das referidas praias. A amostra para o estudo foi constituída por 10 jovens ( 5 de cada praia), tendo-se como critérios, que as mesmas deveriam estar na faixa etária entre 15 e 23 anos de idade e que aceitassem participar do estudo.

O instrumento utilizado para a coleta de dados foi um roteiro de entrevista semi-estruturada (anexo), utilizando-se também, com prévia autorização das mesmas, um gravador como recurso auxiliar.

A coleta de dados desenvolveu-se nos próprios locais de acesso das duas praias, e as entrevistas foram realizadas individualmente no turno da noite, sendo assegurados o anonimato e a privacidade de cada uma, resguardando-lhes o direito, inclusive, de não concluírem a entrevista, se assim o desejassem.

A análise dos dados foi realizada de forma quantiqualitativa, enfocando-se os relatos das entrevistadas. Os dados foram codificados e agregados em núcleos de sentidos, sendo destacados alguns recortes de suas falas, seguindo-se, então, as discussões dos resultados com base na literatura pesquisada. As informações quantitativas foram colocadas no texto, dando assim, melhor qualidade ao problema por nós estudado, como também, fazer uma caracterização do grupo pesquisado.

\section{DISCUSSÃO E ANÁLISE}

Os dados levantados revelam que as jovens do estudo se encontram na faixa etária entre 15 e 23 anos de idade. Quanto à escolaridade das participantes do estudo, $90 \%$ não concluíram o $1^{\circ}$ grau, abandonando a escola entre a $4^{\mathrm{a}}$ e $7^{\mathrm{a}}$ séries; só $10 \%$ das entrevistadas freqüentava a escola, cursando a $3^{\mathrm{a}}$ série do $1^{\mathrm{o}}$ grau. Segundo onde residiam, $80 \%$ moravam em bairros e conjuntos periféricos de Natal, caracterizados por habitações populares e com baixo poder aquisitivo; $20 \%$ eram domiciliadas fora de Natal, ou seja, em municípios do Estado do Rio Grande do Norte. Quanto à qualificação profissional, $80 \%$ não possuíam profissão/ocupação, enquanto que $20 \%$ afirmaram terem uma profissão, ou seja, cabeleireira e operadora de caixa, apesar de não a exercerem. No que se refere à renda familiar, $80 \%$ afirmaram uma renda em torno de 1 a 2 salários mínimos, e $20 \%$ com renda superior a 2 salários mínimos.

Diante das tentativas em identificar as causas que levam as jovens do estudo a fazerem programas sexuais, as 10 entrevistadas apresentaram várias colocações. Destacamos a seguir algumas manifestações neste sentido:

“... comecei porque quis, ele me conheceu fazendo programa, aí ele não se importa, fico aqui, aí depois vou para casa, fico com ele, durmo; foi porque eu quis mesmo, pois eu não quis trabalhar em fábrica de rede, eu sei fazer todo o serviço de rede, mas eu não quis"(E4,22 anos).

“... porque tenho um filho para sustentar, não tenho condiç̃̃es, o jeito então é vir para cá ...” (E6, 15 anos). 
“... com a morte de minha mãe, fui expulsa de casa, aí ficou difícil, não tinha para onde ir, passei muito tempo dormindo na rua, passando fome, necessidade, é horrível fazer programa"'(E7, 19 anos).

“... meus pais não podiam me sustentar, minha mãe morta, a minha vida de programa levou ao seguinte: perdi minha virgindade, aquelas amigas que sempre levam você ao mal, me levaram para esse caminho"(E8, 15 anos).

“... antes eu trabalhava em casa de família, ganhava meio salário por mês, vim depois conhecer a praia, resolvi fazer programa, vi o movimento como é que era e vi que é mais vantagem fazer programa do que trabalhar em casa de família”(E9, 20 anos).

Diante das falas acima, verificamos que as causas que levam as jovens pesquisadas a entrarem no mundo da prostituição, em sua maioria, são de ordem sócioeconômica destacando-se a falta de condições financeiras por parte de seus pais, das jovens para o seu próprio sustento e de seus filhos; o tipo de trabalho com pouca remuneração (fabrica/doméstica) e a expulsão de suas casas pelos próprios pais.

Ao serem questionadas quanto ao tempo que faziam programas, $70 \%$ estão nessa atividade há pelo menos 02 anos, e 30\% há mais de 02 . Diante disto, percebe-se que as entrevistadas permanecem nesse ramo de atividade por falta de alternativas, mesmo sabendo que vão ser obrigadas a abandonarem a prostituição com o avançar da idade, pois, a cada dia, uma adolescente mais jovem surge como sua concorrente, sendo portanto mais valorizada pelos clientes, diante do que foi colocado por uma das entrevistadas:

“... o pai do meu menino não trabalha, quem trabalha sou eu, aqui,... porém, não pretendo ficar aqui a vida toda, pois vou ficar velha e os homens não querem mais, preferem as mais novinhas..." (E4, 22 anos).

Ao serem abordadas porque escolheram aquela via que dava acesso à praia para os acertos dos programas sexuais, mencionamos os seguintes trechos referentes as falas das participantes:

“... porque tem muito movimento...é melhor, tem mais programas...uma pessoa me trouxe para cá, aqui é bom, também não conheço outro lugar..." (E3, 17 anos).

“... antes eu trabalhava em casa de família, ganhava meio salário por mês, vim depois conhecer a praia, resolvi fazer programa, vi o movimento que era e vi que é mais vantagem fazer programas do que trabalhar em casa de família ganhando meio salário por mês” (E9, 20 anos). “Bem, já trabalhei em casa de drink; lá eles gostam muito de humilhar, a gente tem que beber a noite inteira, às vezes nem ganha dinheiro né, mas tem que estar bebendo, farreando, quem ganha é o dono e a gente não ganha nada, a exploração é muito grande" (E10, 23 anos).

Como as vias de acesso às Praias do Meio e de Ponta Negra possuem um intenso fluxo de clientes motorizados, isto leva as entrevistadas a freqüentarem essas áreas com a finalidade de terem um número maior de programas sexuais. Observa-se que, além das prostitutas profissionais, essas jovens também fazem concorrência desses locais com travestis que limitam suas áreas, não permitindo a invasão das mesmas, ante a ameaça de serem agredidas por eles.

Relacionando-se o número de dias e os horários dos programas, $60 \%$ das participantes do estudo trabalham todos os dias da semana e $40 \%$ entre 3 e 5 dias; quanto aos horários, $50 \%$ fazem os programas às tardes e noites, $30 \%$ só às noites e $20 \%$ nos três turnos. No que se refere ao número de programas/dia, $40 \%$ fazem de 3 ou mais programas/dia, enquanto que $60 \%$ até 2 .

Isto reflete a problemática porque passam essas jovens, fazendo com que as mesmas encarem essa atividade como um trabalho fixo com renda variável, passando a maior parte do dia nas ruas onde o números de programas/dia não evidenciam que as mesmas possuam um bom rendimento com essa atividade, pois essa quantidade é bastante variável, e às vezes elas não conseguem realizar nenhum.

Corroborando os turnos da tarde e da noite como os mais valorizados por essas jovens, GARPAR (1985) afirma que:

“... o fazer programa é seu aspecto também diurno, mas é no período noturno que a atividade alcança seu zênite, não tanto pelos maiores ganhos ou pelo maior número de clientes, mas porque seus valores integram, como a boemía, o universo da noite ... no período da tarde, os programas são mais rápidos e seguros, e a clientela é de melhor nível, composta principalmente de profissionais liberais que pretendem ter um pequeno encontro entre o período de saída do trabalho e a ida para a casa ... porém, é durante a noite, que a prostituição é praticada de maneira mais ostensiva nas ruas $e$ bares... ocupada pelas pessoas sem compromisso, que não precisam ter pressa, por aqueles que trabalham como músicos e artistas e ainda, pelos noctívagos, aqueles que saem de madrugada para 
fazer suas refeições, beber, conversar com os amigos até que os últimos bares e restaurantes fechem suas portas" (p.106).

Quanto ao valor cobrado e o que fazem com a renda dos programas sexuais, os depoimentos que se seguem ilustram bem essas situações:

“... faço 2 a 3 e às vezes nen hum... cobro $R \$ 50,00$, 40,00 e às vezes 70,00; às vezes para dormir $R \$$ 100,00 depende...dai compro coisas para meu filho e dou a metade a minha mãe; ela sabe que faço programa..." (E1, 19 anos).

“... depende do dia, se tiver bom 2, 3 até 4, se não estiver bom se faz 1, 2 ... cobro $R \$ 50,00,80,00$ até 100,00 depende, se vir que o homem tem boas condições se cobra muito, de vez em quando um turista paga $R \$ 100,00,150,00 \ldots$ pago as contas, compro comida e sustento meu filho...” (E2, 17 anos).

“... agora tá muito difícil, se fizer 1 tá muito bom, agora com esse negócio de pegar no pé das mulheres de programas, os homens estão com medo,... cobro $R \$ 50,00,30,00 .$. com o dinheiro faço muita coisa, compro comida, roupa, ajudo em casa..." (E7, 19 anos).

“... não relaxo um dia, porque se faltar um dia, passo o dia sem comer e sem fumar, passo o dia inteiro, ... vou dar uma volta e não ganho nada, vou prá casa triste; se não ganhar, no outro dia também não se come uma carne, tem que comer puro, e não dá, né?... quando o movimento tá legal, a gente tá fazendo 1, 2 né, mas quando não tá legal a gente não faz nenhum, ganha mixaria, para não perder a noite às vezes vai por $R \$ 20,00$, coisas assim... com a grana eu compro comida, geralmente não dá para comprar nem os cosméticos ... e outras coisas; primeiro a alimentação; a gente tem que ter uma roupinha legal para vestir, porque os homens não gostam de mulher mal vestida, com mal cheiro, gostam de mulher limpa..." (E10, 23 anos).

Diante das circunstâncias que as adolescentes do estudo buscam para conseguirem algum dinheiro para o sustento da família ou do seu próprio, nem sempre é coberto de êxito, caracterizado pela insegurança financeira, pela incerteza em obterem o sustento almejado com a atividade praticada, tornando-se, a prostituição, um meio instável de manutenção econômica para essas jovens. O que observamos também nas suas falas, é que, além da busca do dinheiro necessário para o sustento, elas precisam investir na própria imagem, como condição indispensável para continuarem exercendo essa atividade.
De acordo com as colocações de GASPAR (1985), em seu estudo, refere que as garotas de programa estão, "diante de sua própria situação de penúria e também da sua família, onde é necessário que ela se sacrifique por ela e pelos seus ... a prostituição surge então como um recurso quase legítimo para a falta de dinheiro" (p. 98).

Quanto as DST/AIDS, as adolescentes do estudo sabem dos riscos a que estão expostas e, em seus depoimentos, o uso da camisinha torna-se indispensável. A exemplo disso, uma delas diz:

“... eu perco programa porque às vezes tem homem que não quer usar a camisinha; só faço com a camisinha porque eles querem que a gente pratique sexo oral, sem camisinha não dá, porque nem ele conhece a gente nem a agente conhece eles e a gente não sabe o que vai ocorrer...” (E9, 20 anos).

Sabemos entretanto, que algumas adolescentes, para ganharem um pouco mais, cobram mais caro dos clientes para não fazerem uso do preservativo.

REVES (1994), em suas pesquisas, refere que as prostitutas estão deixando de ser foco de transmissão de doenças onde a maioria delas só trabalha com preservativos. Entretanto, refere a mesma autora, que a antropóloga Martha Lamas, relata que em conversa com essas mulheres, elas confessam que às vezes os clientes oferecem um pouco mais de dinheiro para terem relações sexuais sem preservativo, o que muitas aceitam.

Sobre esta questão, concluiu GOMES (1996) que, “... entre achar que o preservativo é uma solução e o seu uso propriamente dito vai na grande distância, pois ... entre a consciência e a sobrevivência, a segunda fala mais alto, comprometendo a prevenção. Entre correr o risco de vida e receber o dinheiro, a menina vacila em optar pela segunda alternativa ...”( p.184).

Em relação à associação que se estabelece entre prostituição e violência, a metade $(50 \%)$ das pesquisadas já tinham sofrido algum tipo de agressão, tanto por parte de seus clientes (04) como por outras meninas de programa (01), evidenciando-se, dessa forma, a insegurança e o risco que estão expostas essas jovens durante a realização de suas atividades sexuais, traduzida pelos seguintes depoimentos:

“... com certeza, um homem me pegou, me levou para a via costeira, quis me agarrar a força, eu não quis, ele me chutou do carro" (E5, 19 anos). “... eles arrumam confusão e a gente que é mulher de programa, não tem chance ... a gente acaba 
apanhando no quarto dos homens... os policiais a maioria dá razão a eles ... sabe o que eles inventam? que a gente roubou eles ... sabe onde a gente acaba? na cadeia, às vezes apanhando por coisa que a gente não fez" (E9, 20 anos).

“... já, um rapaz de boa aparência ... me chamou para fazer um programa com ele ... me usou de todas as formas, me machucou, tirou sangue de mim, fez sexo anal e tudo, estupidamente, brutalmente, como se fosse um estrupador" (E10, 23 anos).

Quanto às perspectivas de futuro e ascensão social dessas jovens, estavam muito relacionadas a terem uma profissão, trabalhar e receberem uma renda fixa. Todavia, as próprias pesquisadas não conseguem vislumbrar caminhos ou alternativas que as possibilitem saírem do caminho da prostituição, manifestadas através destas colocações:

“... quero ter uma casa própria, ter um trabalho, mudar de vida ... trabalhar" (E2, 16 anos).

“... espero arrumar algum meio de sair daqui, porque aqui não é lugar ideal da pessoa ficar o resto da vida" (E4, 22 anos).

“... pretendo ter uma vida digna, casar, ter filhos, é o meu sonho, mas é muito dificil” (E8, 15 anos). “... pretendo comprar um carrinho de cachorro quente, ... ter uma renda fixa, sem precisar morar na casa dos outros, pagar meu aluguel" (E10, 23 anos).

Percebe-se, nos depoimentos das jovens do estudo, que a prostituição não é encarada como profissão, mas que tem um caráter de atividade temporária. Identifica-se também, insatisfação, desejo de mudar de vida, e esperança que esta atividade possa atribuir-lhes um caminho, permitindo-lhes de certa forma, juntar dinheiro para algum empreendimento, apesar de seus ganhos reduzidos e das responsabilidades que algumas assumem com o sustento da família e o delas próprias.

\section{CONSIDERAÇÕES FINAIS}

À luz dos resultados obtidos e dos aspectos contemplados nas discussões sobre a temática da prostituição na adolescência, ficou patente que urge uma tomada de decisão por parte dos órgãos responsáveis pelo bem-estar do adolescente como também pela sociedade em geral através de seus grupos organizados, com vistas a traçarem estratégias que possibilitem alternativas e apoio a essas garotas que estão no ramo da prostituição, e principalmente que evitem o ingresso de novas adolescentes nessa atividade.

Nessas discussões, devem ser enfatizados todos os fatores e determinantes causais dessa problemática, como: garantir acesso à escola, a uma profissionalização, e oferecer condições de um trabalho digno que reverta em uma fonte de renda para a própria subsistência das mesmas e de seus familiares, já que a principal causa que levou as jovens do estudo a se prostituírem, segundo seus relatos, foi a falta de condições financeiras. Identificou-se, também, que essas jovens aspiram um futuro melhor, como por exemplo, deixar a prostituição, trabalhar, terem uma profissão e uma vida digna.

Diante do exposto, não queremos aqui ditar fórmulas ou receitas para a retirada dessas jovens da prostituição, pois estamos conscientes que essa problemática merece uma discussão e visão mais ampliada e aprofundada de todo o contexto sócioeconômico-cultural no qual essas garotas estão inseridas. Entretanto, não devemos ficar coniventes com a atual situação da prostituição, principalmente no tratamento e abordagem que está sendo dada pelos órgãos governamentais responsáveis pela integridade e cidadania do adolescente.

\section{PROSTITUTION: REASONS AND FUTURE PERSPECTIVES IN A GROUP OF YOUNG GIRLS}

This is a descriptive exploratory study developed at the city of Natal/RN, through interviews with 10 young girls that made sexual programs at the Meio and Ponta Negra beachs. The purpose was to identify the reasons that made young girls to opt for this activity and the future perspectives of this group. Authors identified that the principal cause that leads these kids to become prostitutes was the lack of financial conditions, and, also, that they believe in future, to be able to work, to leave the prostitution, to have a profession and a better life. Therefore, there is a need for decisions by the responsible agencies and for society in general to give alternatives to these young kids to leave prostitution and mainly to prevent the ingress of new adolescents in this activity. 


\section{PROSTITUCIÓN: CAUSAS Y PERSPECTIVAS DE FUTURO EN UN GRUPO DE JÓVENES}

Este es un estudio de tipo descriptivo exploratorio, fue realizado en una ciudad de Natal/RN, se entrevistaron 10 jóvenes que consiguen clientes en las calles de acceso a las playas del Medio y de Punta Negra. Nosotros teníamos como objetivos, identificar las razones que las condujeron a optar por esta actividad y las perspectivas del futuro de ese grupo de muchachas jóvenes. Como principal resultado, fue identificado que la principal causa que condujo a esas jóvenes a una vida de prostituta fue la escasez de recursos financieros, ellas aspiran en un futuro, dejar la prostitución, trabajar, tener una profesión y una vida digna. Tornase patente entonces, la necesidad de una decisión para los órganos responsables por el bienestar del adolescente, para la sociedad en general, dando a estas niñas jóvenes la alternativa para dejar la prostitución, y principalmente prevenir el ingreso de nuevas adolescentes en ésta actividad.

TÉRMINOS CLAVES: prostitución, adolescencia

\section{ANEXO}

\section{ROTEIRO DE ENTREVISTA}

\section{1 - Caracterização da entrevistada}

1.1. Qual a sua idade?

1.2. Você freqüenta a escola? caso não freqüente, em que série parou de estudar?

1.3. Onde e com quem mora?

1.4. Você tem alguma profissão/ocupação?

1.5. Quanto é aproximadamente a sua renda familiar?

\section{2 - Questões básicas sobre a prostituição}

2.1. O que levou você a fazer programas sexuais?

2.2. Há quanto tempo faz programas sexuais?

2.3. Porque escolheu este local (praia)?

2.4. Quantos dias na semana você faz programas? Quais os horários (manhã/tarde/noite)?

2.5. Você se previne contra as DST/AIDS? O que faz para se prevenir?

2.6. Quantos programas, em média, você faz por dia?

2.7. Quanto você ganha, em média, por um programa?

2.8. O que faz com o dinheiro ganho?

2.9. Já sofreu algum tipo de agressão? De quem?

2.10. O que espera ou pretende fazer no futuro?

\section{REFERÊNCIAS BIBLIOGRÁFICAS}

01. BOSCO FILHO, J. et al. Prostituição de menores em Mossoró/RN. In: CONGRESSO BRASILEIRO DE ENFERMAGEM, 48, São Paulo, 1996. Resumo. São Paulo, 1996. p. 223.

02. BRAGA, J.M.F. Prostituição e moral: evangelização libertadora versus pecado social. In: ÂNGELO, A. et al. A prostituição em debate. São Paulo: Paulinas, 1982. Cap.7, p.59-76.

03. CONFERENNCIA NACIONAL DOS BISPOS DO BRASIL. Comissão Episcopal de Pastoral. Prostituição: desafio à sociedade e a igreja. São Paulo: Paulinas, 1976. 170p.

04. FRANÇA, G.V.de. Prostituição: um enfoque políticosocial. Femina, Rio de Janeiro, v. 22, n.2, p. 145148, fev. 1994.
05. GASPAR, M.D. Garotas de programas: prostituição em Copacabana e identidade social. Rio de Janeiro: Jorge Zahar, 1985. 135p.

06. GOMES, R. O corpo na rua e o corpo da rua: a prostituição infantil feminina em questão. São Paulo: Unimarco, 1996. p.127-139: Ambiente de pobreza: espaço de exclusão social.

07. LAGENEST, J.P.B.de. Lenocínio e prostituição no Brasil. Rio de Janeiro: AIR, 1987. 195p.

08. PELUSO, L.; GOLDBERG, S. Sexo: lucros do prazer. Isto é, São Paulo, n. 1381, p. 88-92, 1996.

09. PROSTITUIÇÃO. Mundo Jovem. Porto Alegre, v. 32, n.251, maio 1994.

10. REVES, I.J. A prostituição mais antiga. Cadernos do Terceiro Mundo, Rio de Janeiro, n. 179, out. 1994.

11. VASCONCELOS, A. A prostituição de meninas e adolescentes no Recife. Tempo e Presença, São Paulo, v. 13, n. 258, p. 22-23, jul./ago. 1991. 